\section{Biometrology in Tissue Engineering: Thoughts and Concepts}

\section{Abstract}

The range of measurement techniques have increased in number and quality in recent decades. Qualitative methods have been increasingly applied to research in biological and health fields. However, Biotechnology and more specifically Tissue Engineering have reached a point that requires a step further. This step will be the adoption of Metrology (metrological standardization and metrological traceability) as a fundamental practice in scientific research and development of new therapeutic approaches. Some of the experience acquired from the production of medical devices and ontological instruments could be applied both for scaffold-based and scaffold-free strategies in Tissue Engineering. Metrological rules can be applied not only for biomaterials but also for tissues built in vitro, as a form of control for tissue maturation. The whole concept of Biometrology should be established as a research field, supporting future research and emerging health therapies, including Tissue Engineering. This review aims to introduce relevant theoretical concepts in Biometrology and their correlation with new approaches in Tissue Engineering.

Keywords: Metrology; Tissue engineering; Biometrology

Received: February 21, 2016; Accepted: March 04, 2016; Published: March 11, 2016

\section{Reproducibility Issues in Tissue Engineering}

Reproducibility is one of the basic assumptions in scientific experiments. If an experiment cannot be reproducible, its outcome cannot be proved and therefore, cannot be accepted [1]. This point has created great difficulties in biological field, for example, microbiology samples are strongly dependent on their strains, sometimes causing results inconsistency from different research groups using their own strains. In many cases there is mis identification or contamination of the samples. These difficulties are also observed in the field of Tissue Engineering.

The expanding field of Tissue Engineering aims to build tissues and organs in vitro from three-dimensional cell culture systems suitable for regeneration, repair and / or replacement of damaged tissue. In order to achieve this goal, cells are cultivated in a threedimensional manner, using scaffold-dependent or scaffold-free strategies [2-6]. The first one is based on the combination of growth factors / genes with cells seeded in natural or synthetic biomaterials, which include ceramics, metal, polymers and decelularized matrices. These biomaterials should create a structural and molecular environment that mimics mechanical,

\section{Leandira S Baptista ${ }^{1,2,5,6}$, Karina R Silva ${ }^{1,2}$, Anderson Beatrici ${ }^{3}$, Giselle N Fontes ${ }^{4}$, José M Granjeiro ${ }^{1,2,5}$ and Leonardo C Boldrini ${ }^{2,5}$}

1 National Institute of Metrology, Quality and Technology - INMETRO, Duque de Caxias, RJ, Brazil

2 Tissue Bioengineering Research Group, National Institute of Metrology Quality and Technology - INMETRO, Duque de Caxias, RJ, Brazil

3 Mass Laboratory, National Institute of Metrology, Quality and Technology INMETRO, Duque de Caxias, RJ, Brazil

4 Laboratory of Microscopy Applied to Life Science, National Institute of Metrology Quality and Technology - INMETRO, Duque de Caxias, RJ, Brazil

5 Translational Biomedicine PostGraduation Program, University of Grande Rio, Duque de Caxias, Rio de Janeiro, Brazil

6 Federal University of Rio de Janeiro(UFRJ) / Xerém, Duque de Caxias, RJ, Brazil

Corresponding author: Leandra S Baptista

” leandra.baptista@gmail.com

Directory of Metrology Applied to Life Science - Dimav, National Institute of Metrology, Quality and Technology (Inmetro), Av. Nossa Senhora das Graças, 50 - Xerém, Duque de Caxias, Brazil.

Tel: +8675586135700

Fax: +55-21-26799837

Citation: Baptista LS, Silva KR, Beatrici A, et al. Biometrology in Tissue Engineering: Thoughts and Concepts. J Sci Ind Metrol. 2016, 1:2.

geometrical and biological properties of the native organ in order to support the recipient's cells [7-9]. The scaffold-free strategy is 
based on the capacity of vertebrate cells to self-organize in vitro in the absence of an adherent surface. It is recently being used to rebuild parts of organs from stem cells that self-assemble to form multi-cellular spheroids or even organoids [10] , as basic units for engineering tissue constructs [11, 12]. Multi-cellular spheroids can be used as building blocks for organ printing technology (a computer-aided robotic layer-by-layer additive bio fabrication of 3D functional tissue and organ constructs), which can achieve organ construction based on the fundamental biophysical principle of intrinsic capacity of multi-cellular spheroids for tissue fusion driven by surface tension forces [12]. These multi-cellular spheroids must have standard size and shape suitable for bio printing process $[12,13]$.

The period of time taken during a bi-dimensional cell culture can influence cell differentiation and function, hampering its application in drug testing $[14,15]$. Currently, three-dimensional multi-cellular spheroids cell culture technique in Tissue Engineering is being considered a valuable tool for toxicity and drug discovery because it could represent a more predictive in vitro method than bi-dimensional cell culture technologies [1619]. Cells in spheroids show morphological features, cytoskeleton remodeling and cell-cell and cell-matrix interactions more similar to in vivo systems, bypassing bi-dimensional culture limitations [20-22]. Likewise, simple-handed methods have been developed to fabricate spheroids with standard size and high yield [23] serving as a basis for the development of highthroughput drug screening platforms based on spheroids. Yet, the current ban of animal tests on cosmetic area [24], the ethical, cost, and time consuming of animal tests, make appropriate cell culture systems indispensable in toxicity and drug discovery and the use of multi-cellular spheroids seems to bridge this gap [14, $15,17,18]$.

Recent findings point to a large number of erroneous and incompatible conclusions published in scientific studies. In addition, \$28 billion are spent every year in the United States on basic biomedical research that cannot be successfully repeated [25]. The overall lack of reproducibility rate estimated exceeds $50 \%[26,27]$, as discussed in several papers [28-30]. Cell strains misidentification, poor control and poor traceability, among others, has been shown in such studies. As an alternative to decrease the lack of reproducibility rate, result traceability could be encouraged, or even required, for research works, whenever applicable.

Cell lines are used in scientific research, drug and biomolecules development and toxicological tests as models for normal and cancer tissues. However, cell-line misidentification and contamination with microorganisms, such as mycoplasma, together with instability, both genetic and phenotypic, are among the issues that continue to affect scientific reproducibility. Unfortunately, thousands of misleading and potentially erroneous papers have been published using cell lines which are incorrectly identified [31, 32].

In order to address the issue of identification, cell banks use STR (short tandem repeat) profiling, which looks at specific DNA sequences that vary in number from one individual to the next one. The technique, which laboratories have long used to genetically fingerprint DNA from blood at a crime scene and paternity tests, can also distinguish cell lines coming from different individuals [33].

Most of such misidentification and contamination issues have appeared in the past 50 years, due to neglect in the application of good practices. The importance of Metrology in cell line studies can be evaluated from two examples cited by Korch and coworkers: HEp-2 (claimed laryngeal carcinoma cell line) and INT 407 (intestinal cells (jejunum / ileum), embryonic cells). Due to contamination at some point in the past, both are now widely acknowledged to be composed of cancer cells called HeLa (cervix adenocarcinoma) [34]. It is estimated that 5,789 articles in 1,182 journals may have used HEp-2 inappropriately, producing about 174,000 citations. Likewise, 1,336 articles in 271 journals may have used INT 407 inappropriately, producing about 40,000 citations. It is projected an amount of $\$ 713$ million spent on the original papers which were published concerning INT 407 and HEp-2 cells, and about $\$ 3.5$ billion spent on subsequent work based on those papers [34].

With the aim to avoid handling problems leading to microbial contamination or cross-cell lines, some guidelines have been suggested [35] as for example:

- Acquiring cell lines from cell banks;

- Recording all relevant data to the origin of the cell lines;

- Checking whether the STR profile is in agreement with published data base (http://www.ncbi.nlm.nih.gov/bios ample?term=human+str+profile Misidentified Cell Lines: http://www.ncbi.nlm.nih.gov/biosample?term=misidentif ied+cell+line) to avoid misidentification;

- Banking authenticated cells for future use and replacing cultures regularly from frozen stock;

- Applying regulations often to the distribution of cell lines and only distributing only authenticated stocks;

- Testing cell lines for mycoplasma contamination.

\section{Metrology Concepts Applied to Biology}

Biometrology (Science of measurement and its applications in the biological and health field) is a relatively new and promising area in the field of Biology. The common sense would say that there are so many variants in any biological system that it would be virtually impossible to track all factors involved in a biological interaction. However, applying metrological concepts during a biological experiment is not impossible and could be the route to track some of these factors. It is reasonable that research laboratories should have to direct their efforts towards global standardization to produce equivalent results [36].

In this sense, during any scientific experiment, two concepts must be kept in mind: repeatability and reproducibility, as they are the components of precision in a measurement system [37]. The first one consists of "condition of measurement, out of a set of conditions that includes the same measurement procedure, same 
operators, same measuring system, same operating conditions and same location, and replicate measurements on the same or similar objects over a short period of time" and reproducibility means "condition of measurement, out of a set of conditions that includes different locations, operators, measuring systems, and replicate measurements on the same or similar objects" [38]. It does not mean that other concepts, as traceability, intercomparison, expanded uncertainty, degrees of freedom etc. are not important. Furthermore components of precision*, accuracy* and trueness* must be reminded (Glossary).

Keeping these concepts in mind, a good starting point to apply metrological concepts to biology experiments could be:

- Applying Metrology in biological procedures e.g. Calibrating pipettes (automatic and manual ones), glassware, scales etc.; writing and defining very accurate protocols for cell cultures and other laboratory procedures - e.g. Mycoplasmas contamination tests [39] and authentication by STR profile tests [31].

- Measuring physical phenomena that arise from any biological interactions [40].

- Creating reference material from very well-known biological material or any material of biological interest - e.g.: "Protocol for Preparing Febrile Collagen Matrices on Untreated Polystyrene Lab ware (Petri): A Potential Reference Extracellular Matrix With Robust and Reproducible Cell Responses" [41].

The next topic contains good examples on how metrological concepts could be applied in Tissue Engineering approaches.

\section{Metrology as a Guidance for Standards in Tissue Engineering}

Multiple efforts have been made to apply metrological concepts to the biomedical area, especially for medical devices cytotoxicity evaluation and ontological instruments production [42, 43]. In Tissue Engineering area, biomechanical analyses have been used to evaluate mechanical properties of biodegradable scaffolds applied for surgeries [44-46] or decelularized organs, as pancreas [47] and heart [48, 49].

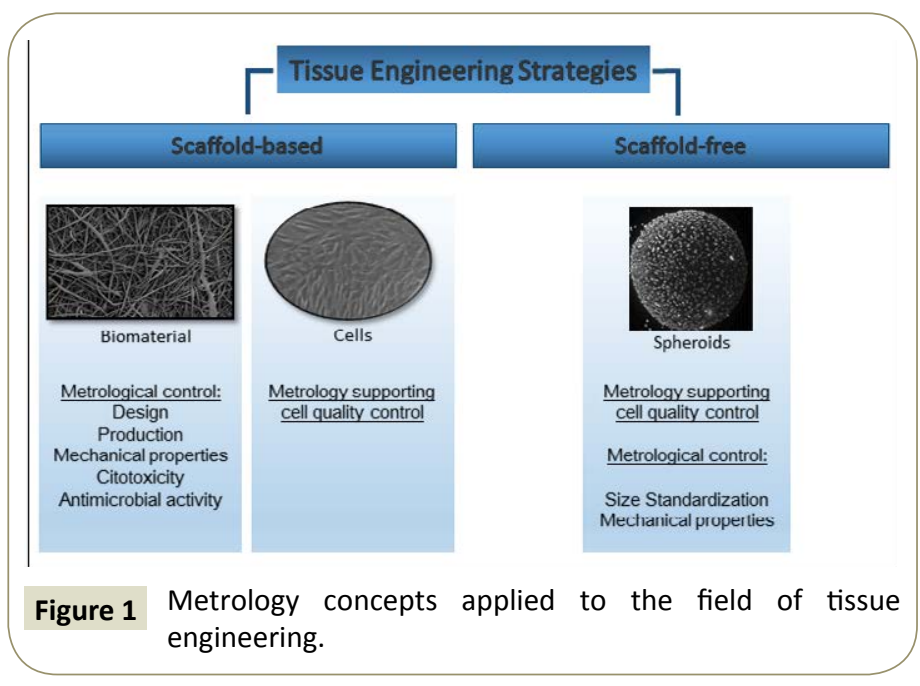

Nonetheless, there is scarce information regarding Metrology applied to the field of Tissue Engineering. Some of the experience acquired from the production of medical devices and ontological instruments could be applied both for scaffold-based and scaffold-free strategies in Tissue Engineering (Figure 1). In the first case, it can be achieved by applying metrological rules to the biomaterial design, production, mechanical properties (based on Materials Science Concepts) and cytotoxicity measurements, and by supporting quality control of cells' identity and culture's microbiological contamination. For the scaffold-free strategy, metrological concepts must support quality control of cell culture, but also support mechanical properties characterization of spheroids, as a control of tissue maturation [50].

Metrological traceability is not restricted to the scales, glassware, etc. (as exposed in topic 2). It also involves the measurement model and the measurement system. Providing traceability to the measurement results and reference material properties involve:

- Metrological traceability in all measured quantities.

For instance, the superficial tension in a cellular spheroid using Laplace equation [51] depends on three curvature radii length and the applied force magnitude in the sample, all related quantities in the measurement model must present metrological traceability in the SI units, in this case, the force and length.

- Measurement procedures standardization.

The measurement outcome may depend on measurement procedure. For instance, on determining the mass using a microgram scale (Class I balance [52]), factors like sample thermal stabilization time, weighing stabilization time and eccentricity can strongly affect balance indication. The whole weighing procedure must be precisely established to avoid measurement errors.

- Measurement model validation.

Most of measurement results come from indirect measurements, when other quantities are measured (input quantities) from which we obtain the intended quantity (output quantity). Mathematical relations, software, automatic data acquiring must be analytically or experimentally validated.

- Uncertainty budget validation.

It should be noted that the measurement standard deviation is only one of many possible measurement uncertainty components associated to a result. Uncertainty budget comes from a model that takes into account all type $A$ and type $B$ components for evaluation of measurement uncertainty. The model (influence quantities, calculations and results) must be validated in order to verify that the modeling provides the real effect of each identified uncertainty component in the uncertainty budget [53].

- Interlaboratory comparisons (Proficiency Testing Programmes). 
This step certifies the laboratory measurement capabilities.

Adopting standardization and traceability as mandatory for biological assays not only contributes to a better reliability of research results, but also assists referees in assessing results viability, decreasing the number of studies being questioned.

In addition, the final construct (i. e., the result of cells seeded on a chemically-defined biomaterial or the result of fused spheroids) must also be analyzed according to metrological rules. Tissueengineered constructs are incubated in perfusion bioreactors for tissue maturation, a process that simultaneously includes cell proliferation, migration and cellular differentiation. Tissue Engineered blood vessels and heart valves, for example, take several months to achieve desirable levels of tissue maturation $[54,55]$. Many complex histological, biochemical and molecular features are evaluated to determine the maturation level and could be subjected to metrological rules. An increased level of tissue cohesion mediated by cell adhesion molecules such as cadherins [56] and deposition of extracellular matrix molecules $[57,58]$ also occurs during tissue maturation, influencing tissue mechanical properties [50]. Tissue construct mechanical properties estimation can be a valuable, easier and cost-effective tool for screening tissue maturation. Metrological rules can be applied for any in vitro built tissues, as a form of control tissue maturation. Nevertheless, this area still lacks reference materials to improve engineered tissue maturation in vitro.

The whole concept of Biometrology should be established as a research field, supporting future research and emerging health therapies, including Tissue Engineering. Thereby, in a near future, tissues and organs generated by tissue engineering approaches could have a better characterization and production, being the characterization procedures and production protocols able to certificate whether or not their properties are similar or even better than native tissues.

\section{Acknowledgement}

Financial Support from the Brazilian Ministry of Science and Technology (CNPq) and by Rio de Janeiro State Government (FAPERJ).

\section{Disclosure of Interests}

Authors declare no potential conflicts of interest relevant to this article. 


\section{References}

1 Lakatos EV, Marconi MA (2007) Methodological scientific 5.

2 Tibbitt MW, Anseth KS (2009) Hydrogels as Extracellular Matrix Mimics for 3D Cell Culture. Biotechnol bioeng 103: 655-663.

3 Haycock JW (2010) 3D cell culture: a review of current approaches and techniques. Methods Mol Biol 695: 1-15.

4 Fennema E, Rivron N, Rouwkema J, van Blitterswijk C, de Boer J (2013) Spheroid culture as a tool for creating 3D complex tissues. Trends Biotechnol 31: 108-115.

5 Langenbach F, Naujoks C, Smeets R, Berr K, Depprich R, et al. (2013) Scaffold-free micro tissues: differences from monolayer cultures and their potential in bone tissue engineering. Clin Oral Investig 17: 9-17.

6 Hinderer S, Layland SL, Schenke Layland K (2015) ECM and ECM-like materials - Biomaterials for applications in regenerative medicine and cancer therapy. Adv Drug Deliv Rev 97: 260-269.

7 Peloso A, Dhal A, Zambon JP, Li P, Orlando G, et al. (2015) Current achievements and future perspectives in whole-organ bioengineering. Stem Cell Res Ther 6: 107.

8 Place ES, Evans ND, Stevens MM (2009) Complexity in biomaterials for tissue engineering. Nat Mater 8: 457-470.

9 Lutolf MP, Hubbell JA (2005) Synthetic biomaterials as instructive extracellular microenvironments for morphogenesis in tissue engineering. Nat Biotechnol 23: 47-55.

10 Lancaster MA, Knoblich JA (2014) Organogenesis in a dish: modeling development and disease using organoid technologies. Science 345: 1247125.

11 Kinney MA, Hookway TA, Wang Y, McDevitt TC (2014) Engineering three-dimensional stem cell morphogenesis for the development of tissue models and scalable regenerative therapeutics. Ann Biomed Eng 42: 352-367.

12 Mironov V, Visconti RP, Kasyanov V, Forgacs G, Drake CJ, et al. (2009) Organ printing: tissue spheroids as building blocks. Biomaterials 30 : 2164-2174.

13 Mironov V, Kasyanov V, Drake C, Markwald R (2008) Organ printing: promises and challenges. Regen Med 3: 93-103.

14 Rimann M, Graf Hausner U (2012) Synthetic 3D multicellular systems for drug development. Curr Opin Biotechnol 23: 803-809.

15 Pampaloni F, Reynaud EG, Stelzer EH (2007) The third dimension bridges the gap between cell culture and live tissue. Nat Rev Mol Cell Biol 810: 839-845.

16 Xia L, Sakban RB, Qu Y, Hong X, Zhang W, et al. (2012) Tethered spheroids as an in vitro hepatocyte model for drug safety screening. Biomaterials 33: 2165-2176.

17 Achilli TM, McCalla S, Meyer J, Tripathi A, Morgan JR (2014) Multilayer spheroids to quantify drug uptake and diffusion in 3D. Mol Pharm 11: 2071-2081.

18 Ranga A, Gjorevski N, Lutolf MP (2014) Drug discovery through stem cell-based organoid models. Adv Drug Deliv Rev 19-28.

19 Wang Z, Luo X, Anene Nzelu C, Yu Y, Hong X, et al. (2015) HepaRG culture in tethered spheroids as an in vitro three-dimensional model for drug safety screening. Appl Toxicol 35: 909-917.

20 Napolitano P, Chai P, Dean M, Morgan R (2007) Dynamics of the self- assembly of complex cellular aggregates on micromolded nonadhesive hydrogels. Tissue eng 13: 2087-2094.
21 Achilli M, Meyer J, Morgan R (2012) Advances in the formation, use and understanding of multi-cellular spheroids. Expert Opin Biol Ther 12: $1347-1360$.

22 Knight E, Przyborski S (2015) Advances in 3D cell culture technologies enabling tissue-like structures to be created in vitro. J Anat 227: 746-756.

23 Napolitano AP, Dean DM, Man AJ, Youssef J, Ho DN, et al. (2007) Scaffold-free three-dimensional cell culture utilizing micromolded nonadhesive hydrogels. Bio Techniques 43: 496-500.

24 Palmer N (2015) Global Cosmetic Compliance Summit. Global Cosmeic Compliance.

25 Loannidis JPA (2005) Why most published research findings are false. PLoS Med 2: e124.

26 Freedman LP, Inglese J (2014) The increasing urgency for standards in basic biologic research. Cancer Res 74: 4024-4029.

27 Freedman LP, Cockburn IM, Simcoe TS (2015) The Economics of Reproducibility in Preclinical Research. PLoS Biol 13: e1002165.

28 Freedman L (2013) Reproducibility: Life sciences lag in stringent standards. Nature 504: 376.

29 Begley CG, Buchan AM, Dirnagl U (2015) Robust research: Institutions must do their part for reproducibility. Nature 525: 25-27.

30 Baker M (2016) How quality control could save your science. Nature 529: 456-458.

31 American Type Culture Collection Standards Development Organization Workgroup ASN-0002 (2010) Cell line misidentification: the beginning of the end. Nat Rev Cancer 10: 441-448.

32 Yu M, Selvaraj SK, Liang-Chu MM, Aghajani S, Busse M, et al. (2015) A resource for cell line authentication, annotation and quality control. Nature 520: 307-311.

33 Barallon R, Bauer SR, Butler J, Capes-Davis A, Dirks WG, et al. (2010) Recommendation of short tandem repeat profiling for authenticating human cell lines, stem cells, and tissues. In Vitro Cell Dev Biol Anim 46: 727-732.

34 Neimark J (2015) Line of attack. Science 347: 938-940.

35 Geraghty RJ, Capes-Davis A, Davis JM, Downward J, Freshney RI, et al. (2014) Cancer Research UK Guidelines for the use of cell lines in biomedical research. Br J Cancer 111: 1021-1046.

36 Armbruster D, Miller RR (2007) The Joint Committee for Traceability in Laboratory Medicine (JCTLM): A Global Approach to Promote the Standardization of Clinical Laboratory Test Results. Clin Biochem Rev 28: 105-114.

37 ISO 21748 (2010) Guidance for the use of repeatability, reproducibility and trueness estimates in measurement uncertainty estimation. International Organization for Standardization 1.

38 VIM (2012) International vocabulary of metrology - Basic and general concepts and associated terms. JCGM 3.

39 Falagan Lotsch P, Lopes TS, Ferreira N, Balthazar N, Monteiro AM, et al. (2015) Performance of PCR-based and Bioluminescent assays for mycoplasma detection. J Microbiol Methods 118: 31-36.

40 Taroni A (2015) Quantum biometrology. Nature Physics 11: 297.

41 http://www.nist.gov/mml/bbd/cell_systems/collagen-filmsprotocol.cfm.

42 ISO-10993 (2009) Biological evaluation of medical devices. ANSI/ADA Specification 101-2001. 
43 Jonnalagadda JB, Rivero IV, Dertien JS (2015) In vitro chondrocyte behavior on porous biodegradable poly(e-caprolactone) / polyglycolic acid scaffolds for articular chondrocyte adhesion and proliferation. J Biomater Sci Polym 26: 401-419.

44 Kajbafzadeh AM, Tourchi A, Mousavian AA, Rouhi L, Tavangar SM, et al. (2014) Bladder muscular wall regeneration with autologous adipose mesenchymal stem cells on three-dimensional collagenbased tissue-engineered prepuce and biocompatible nanofibrillar scaffold. J Pediatr Urol 10: 1051-1058.

45 Pietrzak WS (2012) Creep analysis of PLLA: PGA copolymer craniofacial plates. J Craniofacial Surg 23: 1507-1512.

46 Goh SK, Bertera S, Olsen P, Candiello JE, Halfter W, et al. (2013) Perfusion-decellularized pancreas as a natural 3D scaffold for pancreatic tissue and whole organ engineering. Biomaterials 34: 6760-6772.

47 Ott HC, Matthiesen TS, Goh SK, Black LD, Kren SM, et al. (2008) Perfusion-decelularized matrix: using nature's platform to engineer a bio artificial heart. Nat Med 14: 213-221.

48 Wang B, Boraziani A, Tahai M, Curry AL, Simionescu DT, et al. (2010) Fabrication of cardiac patch with decelularized porcine myocardial scaffold and bone marrow mononuclear cells. J Biomed Mater Res A 94: 1100-1110.

49 Panadero JA, Lanceros Mendez S, Ribelles JL (2016) Differentiation of mesenchymal stem cells for cartilage tissue engineering: Individual and synergetic effects of three-dimensional environment and mechanical loading. Acta Biomater pii S1742-7061(16)30037-X.

50 Norotee C, Marga F, Neagu A, Kosztin I, Forgacs G (2008) Experimental evaluation of apparent tissue surface tension based on exact solution of the Laplace equation. EPL 81: 46003.

51 OIML R76-1 (2006) International Organization of Legal Metrology. Non-automatic weighing instruments. Part 1: Metrological and technical requirements.

52 GUM - Evaluation of measurement data: Guide to the expression of uncertainty in measurement (2008) BIPM 1.

53 Balguid A, Mol A (2009) Hypoxia induces near-native mechanical properties in engineered heart valve tissue. Circulation 119: 290-297.

54 Konig G, McAllister TN (2009) Mechanical properties of completely autologous human tissue engineered blood vessels compared to human saphenous vein and mammary artery. Biomaterials 30: 1542-1550.

55 Steinberg MS, Takeichi M (1994) Experimental specification of cell sorting, tissue spreading, and specific spatial patterning by quantitative differences in cadherin expression. Proc Natl Acad Sci USA 91: 206-209.

56 Robinson EE, Zazzali KM (2003) Alpha5beta1 integrin mediates strong tissue cohesion. J Cell Sci 116: 377-386.

57 Xu Q, Norman JT (2007) In vitro models of TGF-beta-induced fibrosis suitable for high-throughput screening of antifibrotic agents. Am J Physiol Renal Physiol 293: 631-640. 